\title{
The Vasotocin-Like Biological Activity Present in the Bovine Pineal Is Due to a Compound Different from Vasotocin
}

\author{
P. Pévet ${ }^{1,2}$, C. Neacșu ${ }^{3}$, F. C. Holder ${ }^{4}$, A. Reinharz ${ }^{5}$, \\ J. Dogterom ${ }^{1}$, R. M. Buijs ${ }^{1}$, J. M. Guerné ${ }^{4,6}$, \\ and B. Vivien-Rœls ${ }^{4,7}$
}

1 The Netherlands Institute for Brain Research, Amsterdam, The Netherlands, 2 Department of Anatomy and Embryology, University of Amsterdam, The Netherlands, ${ }^{3}$ Institute of Cellular Biology and Pathology, Bucharest, Romania, ${ }^{4}$ Laboratoire de Physiology Comparée des Régulations, CNRS, Strasbourg, France,

${ }^{5}$ Division of Endocrinology, Department of Medicine, Hôpital Cantonal, Geneva, Switzerland, ${ }^{6}$ Laboratoire de Physiologie Général, Université Louis Pasteur, Strasbourg, France, ${ }^{7}$ Laboratoire de Zoologie et d'Embryologie expérimentale, Université Louis Pasteur, Strasbourg, France

\section{With 1 Figure}

Received February 20, 1981

\section{Summary}

The vasotocin-like biological activity detected in an extract ( $\mathrm{E}_{5}$ fraction) of bovine pineal gland was found not to be due to the presence of vasotocin, vasopressin or oxytocin. The data obtained by means of bio- and radioimmunoassays suggest that the peptide responsible for this biological activity, however, possesses the same Pro-Arg-Gly $\left(\mathrm{NH}_{2}\right)$ tripeptidic carboxy-terminal end as vasotocin.

\section{Introduction}

In 1963, Milcu, Pavel, and Neacş discovered in extracts of bovine pineal glands a peptide with vasopressor and oxytocic activities. Since the biological and chromatographic characteristics of this peptide were similar to those of vasotocin (AVT), the authors concluded that 
this pineal peptide was "arginine vasotocine or a hormone with similar structure". In 1966, Pavel and Petrescu compared the antigonadotropic effects of this purified peptide with those of synthetic AVT and concluded that the peptide was identical with AVT. However, in 1972 Neacş, a co-author of the 1963 paper, after a chemical analysis asserted that this peptide (termed by him $\mathrm{E}_{5}$ fraction) was different from AVT and was composed of 14 amino-acids.

Subsequently, Pavel and his group, still using the bioassay approach, concluded: that the pineal gland of all mammals so far examined, including man, contained AVT (or lysin vasotocin, in pigs), that AVT was synthesized by the ependymal cells in the pineal recess and by the cells of the subcommissural organ (SCO), and that AVT was released into the CSF (for references, see Pavel, 1978). These conclusions were largely supported by the radioimmunoassay detection of AVT in the pineal of different mammalian species (Rosenbloom and Fisher, 1975 a; Fernstrom et al., 1980) and in the rabbit SCO (Rosenbloom and Fisher, 1975 b), the immunocytochemical detection of AVT in the rat pineal (Bowie and Herbert, 1976), and especially by the chemical characterization-by means of amino-acid analysis and mass spectrometry-of AVT in bovine pineal gland (Cheesman, 1970). As, moreover, exogenously administered AVT appears to be inhibitory to many aspects of reproduction (for review see Vaughan and Blask, 1978), it is easy to understand why, despite of the fact that the presence of AVT in the pineal was always contested (Ebels et al., 1965), most of the authors have completely forgotten the conclusion raised by Neacsu (1972).

Recently, using a specific radioimmunoassay for AVT, Dogterom et al. $(1979,1980)$ and Negro-Vilar et al. (1980) were unable to demonstrate AVT immunoreactivity in the mammalian pineal gland. It was also observed that the AVT immunoreactivity obtained by means of immunocytochemistry in rat pineal was due to an immunoreaction of the antiserum with an unidentified compound (Pévet et al., 1980 a). Moreover, it has been demonstrated that the neurophysins observed in the pineal-assumed to indicate the presence of AVT (see Pavel, 1978)-were only the carrier proteins of vasopressin (AVP) and oxytocin (OT) (Pévet et al., 1980 b). Their presence (Dogterom et al., 1979, 1980) was explained by the occurrence in the pineal of fibres originating from the hypothalamic magnocellular nuclei (Buijs and Pévet, 1980). However, using another AVT-bioassay than that of Pavel's group, we were able to find an AVT-biological activity in the pineal of several mammals (Holder et al., 1981; Pévet et al., 1981). This made it necessary to reconsider Neacsu's conclusion (1972) that the AVT-biological activity in the mammalian pineal was due 
to a compound different from AVT itself. We have therefore tested the biological and immunological activities of the $\mathrm{E}_{\overline{5}}$ bovine pineal fraction, prepared by Dr. Neacşu according to the original procedure (Milcu et al., 1963).

\section{Materials and Methods}

After preparation by Dr. Neacşu, the $\mathrm{E}_{\bar{j}}$ fraction was sent to Amsterdam by airmail. For comparison, bovine pineals obtained from Pel-Freez Biological Inc., Rogers, Arkansas, U.S.A., were used. They arrived in solid $\mathrm{CO}_{2}$ and were stored at $-70{ }^{\circ} \mathrm{C}$ until used. All experiments reported in the present paper have been done independently in different laboratories by different teams, none of which had any knowledge of the results obtained by the others.

Radioimmunoassays for AVT, AVP and OT (radioimmunoassaysAmsterdam). The three radioimmunoassays which discriminate between all three hormones and measure them in the same sample, were developed in the Netherlands Institute for Brain Research, Amsterdam. The procedure used in our laboratory for raising antibodies, the preparation and purification of labelled hormones, the preparation of the standard curve and the extraction of the hormones from the sample by means of activated vycor glass powder have been described earlier (Dogterom et al., 1977, 1980).

Radioimmunoassay for $A V T / A V P$ (radioimmunoassay-Geneva). In the radioimmunoassay for AVP/AVT, developed by the Division of Endocrinology of the Cantonal Hospital in Geneva, an antibody against the last three amino-acids of AVP or AVT, i.e., Pro-Arg-Gly $\left(\mathrm{NH}_{2}\right)$, was used. The procedure and the characteristics of this RIA have been published previously (Czernichow et al., 1974).

Bioassay (Strasbourg). A new and very sensitive bioassay for AVT was used which is based on the capacity of AVT to induce, in vitro, isometric contractions in eel ventral aorta strip mounted in a small perspex microchamber. This bioassay has been described earlier (Holder and Guerné, 1976; Holder et al., 1981).

\section{Results and Discussion}

The results obtained with the $\mathrm{E}_{5}$ bovine pineal fraction are represented in Table 1 . With the specific and sensitive RIAs developed in Amsterdam no immunoreactivity for AVT, AVP or OT could be detected in this fraction. This confirms the findings of Milcu et al. (1963) that the vasopressor and oxytocic activities observed in this fraction were not due to AVP or OT. It also confirms the conclusion of Neacsu (1972) that AVT was not present in the fraction. However, our findings obtained with the bioassay demonstrated the presence of an AVT-like biological activity in the $\mathrm{E}_{5}$ fraction and thus confirmed again the work of Milcu et al. (1963). 
P. Pévet et al.:




The RIA for AVT/AVP developed in Geneva made use of an antibody against the tripeptidic carboxyterminal end of AVP or AVT, i.e., Pro-Arg-Gly $\left(\mathrm{NH}_{2}\right)$. This antibody is probably also able to react with other compounds ending by Pro-Arg-Gly $\left(\mathrm{NH}_{2}\right)$ as suggested by the fact that it could react with the synthetic tripeptide Pro-Arg-Gly $\left(\mathrm{NH}_{2}\right)$ (Czernichow et al., 1974). With this RIA we have found an immunoreactivity in the $\mathrm{E}_{5}$ fraction the dilution curve of which was exactly parallel to the standard (here AVP) (Fig. 1). Moreover, after incubation of $\mathrm{E}_{5}$ with trypsin, the antibody did not longer bind this peptide. This implies that the peptide present in this fraction is most probably terminating by Pro-Arg-Gly $\left(\mathrm{NH}_{2}\right)$, a result in accordance with Neacsu's observation (1971) unfortunately published only in abstract form. An AVT-biological activity is also found in the bovine pineal gland (cf. Table 2). This AVT-biological activity, however, is very low. In view of the properties of the bioassay especially vis-à-vis of AVP and OT (Holder et al., 1981), this low AVT-biological activity cannot be attributed to the presence of AVP or OT. It appears therefore that a compound different from AVT but with a biological activity similar to that of AVT is also detectable in the intact bovine pineal. As a consequence it is possible to assert that the results obtained with the $E_{5}$ fraction are not due to the procedure used to isolate the fraction.

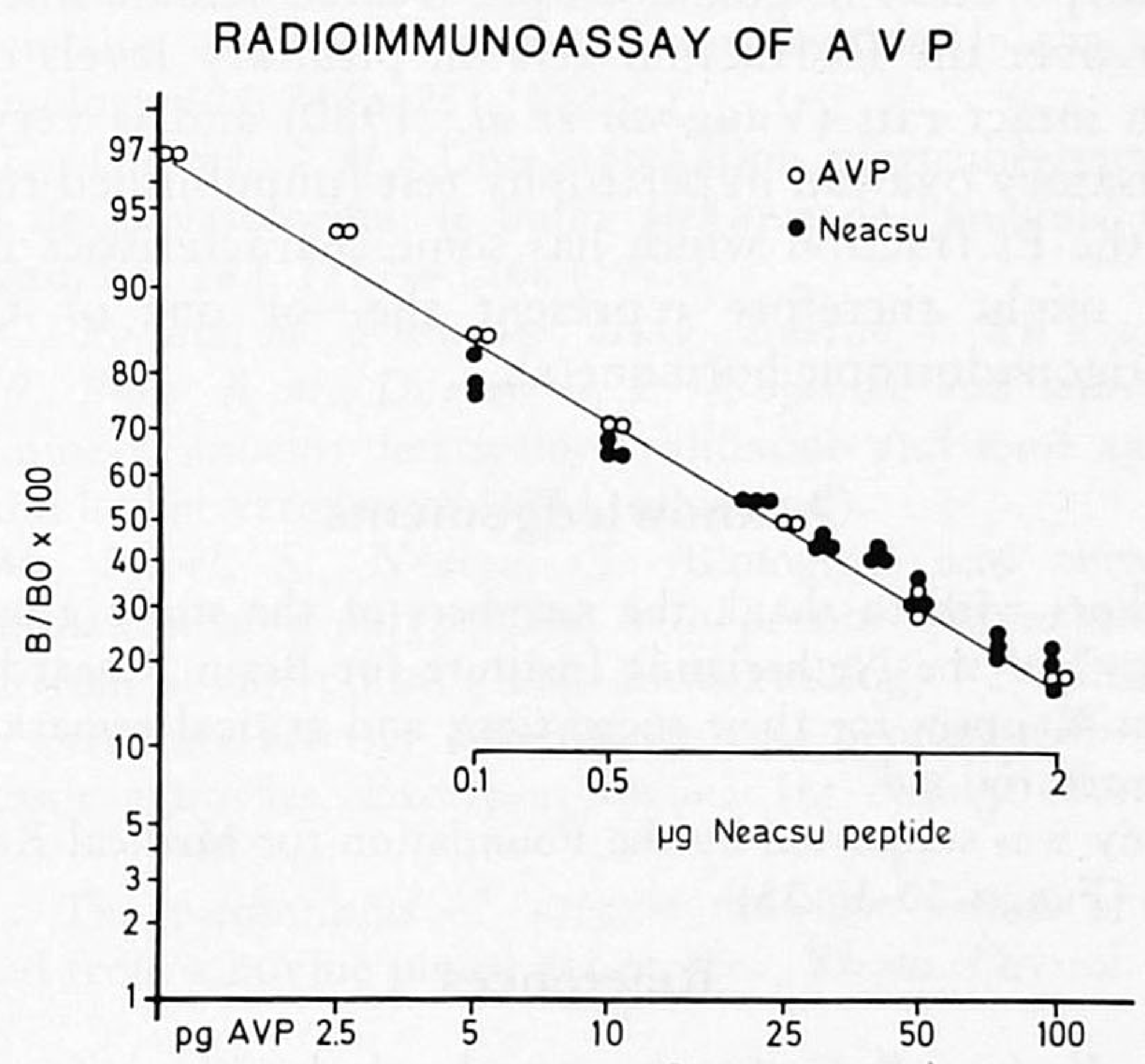

Fig. 1. Representative standard curve of AVP with Pro-Arg-Gly $\left(\mathrm{NH}_{2}\right)$-antiserum and cross reaction curve with the $\mathrm{E}_{5}$ fraction of Neacs $s$ 
As synthetic AVT is being used as reference in the bioassay (Holder and Guerné, 1976), the results are expressed in equivalents of synthetic AVT. It is evident that the value found does not correspond with the real amount which, the peptide being not identified, cannot be determined.

From these different results we conclude that in the bovine pineal a compound is present, which differs from AVT but probably ends, as AVT, by Pro-Arg-Gly $\left(\mathrm{NH}_{2}\right)$ and is responsible of the AVTbiological activity. This conclusion is strengthened by the fact that, applying two non-related techniques, the bioassay used and the Geneva RIA, approximately the same values were obtained (Table 1).

These results contradict the conclusion of Pavel and his group that AVT is a pineal hormone. However, this contradiction may only be apparent. On the one hand, by denying the presence of AVT in the bovine pineal as well as in the pineal of other mammals (Dogterom et al., 1979, 1980; Pévet et al., 1979, 1980 a) we contest the conclusion of Pavel (see details in Pavel, 1978). On the other hand, however, our bioassay findings in the bovine pineal as well as in that of many other species (Holder et al., 1981; Pévet et al., 1981), confirm the experimental basis of Pavel's work.

In connection with the present findings it is of interest to recall that the $\mathrm{E}_{5}$ bovine pineal fraction blocks spermatogenesis in gonadotropin-treated male frogs (Neacşu, 1972) and inhibits uterine weights and $\mathrm{P}^{32}$ incorporation in gonadotropin-treated female mice (Neacşu, 1972). Moreover the $E_{5}$ fraction acts on pituitary levels of LH and prolactin in intact rats (Vaughan et al., 1980) and is very active in the compensatory ovarian hypertrophy test (unpublished results). The peptide in the $\mathrm{E}_{5}$ fraction which has some characteristics in common with AVT might therefore represent the-or one of the-pineal peptidic antigonadotropic hormone(s).

\section{Acknowledgements}

The authors wish to thank the members of the study group "Neuroendocrinology" of the Netherlands Institute for Brain Research and Prof. Dr. J. Ariëns Kappers for their suggestions and critical remarks, and Miss J. Sels for secretarial aid.

This study was supported by the Foundation for Medical Research, The Netherlands (Fungo, 13-35-33).

\section{References}

Bowie, E. P., Herbert, D. C.: Immunocytochemical evidence for the presence of arginine vasotocin in the rat pineal gland. Nature (Lond.) 261, 66 (1976). 
Buijs, R. M., Pévet, P.: Vasopressin and oxytocin containing fibres in the pineal gland and subcommissural organ of the rat. Cell Tiss. Res. 205, $11-17$ (1980).

Cheesman, D.W.: Structure elucidation of a gonadotrophin-inhibiting substance from the bovine pineal gland. Biochim. Biophys. Acta 207, 247-253 (1970).

Czernichow, P., Reinharz, A., Valloton, M. B.: Immunochemical analysis of rabbit antibodies against vasopressin. Immunochemistry 11, 47-53 (1974).

Dogterom, J., Snijdewint, F. G. M., Pévet, P., Buijs, R. M.: On the presence of neuropeptides in the mammalian pineal gland and subcommissural organ. In: The Pineal Gland of Vertebrates including Man (Ariëns Kappers, J., Pévet, P., eds.), pp. 465-470. (Progress in Brain Research, Vol. 52.) Amsterdam: Elsevier. 1979.

Dogterom, J., Snijdewint, F. G. M., Pévet, P., Swaab, D. F.: Studies on the presence of vasopressin, oxytocin and vasotocin in the pineal gland, subcommissural organ and foetal pituitary gland: Failure to demonstrate vasotocin in mammals. J. Endocr. 84, 115-123 (1980).

Dogterom, J., Van Wimersma Greidanus, Tj. B., Swaab, D. F.: Evidence for the release of vasopressin and oxytocin into the cerebrospinal fluid: measurements in plasma and CSF of intact and hypophysectomized rats. Neuroendocrinol. 24, 108-111 (1977).

Ebels, I., Versteeg, D. H.G., Vliegenthart, J.F.G.: An attempt to isolate arginine vasotocin from sheep and bovine pineal body. Proc. Roy. Netherl. Acad. Sci. B68, 1-9 (1965).

Fernstrom, J. D., Fisher, L. A., Cusack, B. M., Gillis, M. A.: Radioimmunologic detection and measurement of nonapeptides in the pineal gland. Endocrinology 106, 243-251 (1980).

Holder, J.C., Guerné, J. M.: Une préparation particulièrement sensible à l'action de la vasotocine: le bulbe aortique de l'anguille d'eau douce. C.R. Acad. Sci. 283, 1767-1768 (1976).

Holder, F. C., Pollatz, M., Schroeder, M. O., Guerné, J. M., Vivien-Rœls, B., Pévet, P., Buijs, R. M., Dogierom, J.: A specific and sensitive bioassay for arginine-vasotocin: description, validation and some applications in lower and higher vertebrates (1981, submitted).

Milcu, S.M., Pavel, S., Neacş, C.: Biological and chromatographic characterization of a polypeptide with pressor and oxytocic activities isolated from bovine pineal gland. Endocrinology 72, 563-566 (1963).

Neacş, C.: Structure-activity data on a pineal peptide with oxytocic and vasopressor activities. Excerpta Medica Int. Congr. Series 241, 275 (1971).

Neacsu, C.: The mechanisms of antigonadotropic action of polypeptide extracted from a bovine pineal gland. Rev. Roum. Physiol. 9, 161-169 (1972).

Negro-Vilar, A., Sanchez-Franco, F., Kwiatkowski, M., Samson, W.K.: Failure to detect radioimmunoassayable arginine vasotocin in mammalian pineals. Brain Res. Bull. 4, 789-792 (1980). 
Pavel, S.: Arginine vasotocin as a pineal hormone. J. Neural Transm., Suppl. 13, pp. 135-155. Wien-New York: Springer. 1978.

Pavel, S., Petrescu, S.: Inhibition of gonadotrophin by a highly purified pineal peptide and by synthetic arginine-vasotocin. Nature 212, 1054 (1966).

Pévet, P., Buijs, R.M., Dogterom, J., Vivien-Rœls, B., Holder, F. C., Guerné, J.M., Reinharz, A., Swaab, D.F., Ebels, I., Neacsu, C.: Peptides in the mammalian pineal gland. In: Pineal Function (Matthews, C., Seamark, R. F., eds.). Amsterdam: Elsevier/North Holland. Biomedical Press (in press, 1981).

Pévet, P., Ebels, I., Swaab, D.F., Mud, M.T., Arimura, A.: Presence of AVT-, $\alpha$-MSH-, LHRH- and somatostatin-like compounds in the rat pineal gland and their relationship with the UM05R pineal fraction: An immunocytochemical study. Cell Tiss. Res. 206, 341-353 (1980 a).

Pévet, P., Dogterom, J., Buijs, R. M., Reinharz, A.: Is it the vasotocin or a vasotocin-like peptide which is present in the mammalian pineal and subcommissural organ? J. Endocrinol. 80, 49 (1979).

Pévet, P., Reinharz, A.C., Dogterom, J.: Neurophysins, vasopressin and oxytocin in the bovine pineal gland. Neurosci. Lett. 16, 301-306 (1980 b).

Rosenbloom, A. A., Fisher, D. A.: Radioimmunoassayable AVT and AVP in adult mammalian brain tissue: comparison of normal and Brattleboro rats. Neuroendocrinol. 17, 354-361 (1975 a).

Rosenbloom, A. A., Fisher, D. A.: Arginine vasotocin in the rabbit subcommissural organ. Endocrinology 96, 1038-1039 (1975 b).

Vaughan, M.K., Blask, D. E.: Arginine vasotocin-A search for its function in mammals. In: The Pineal and Reproduction (Reiter, R. J., ed.), Vol. 4, pp. 99-115. Basel: Karger. 1978.

Vaughan, M.K., Johnson, L. Y., Pévet, P., Neacsu, C., Reiter, R. J.: Effect of a polypeptide $\left(E_{5}\right)$ extracted from bovine pineal glands on plasma and pituitary levels of luteinizing hormone (LH) and prolactin in normal and castrated adult male rats. 10th Ann. Meeting Soc. Neurosci., 9-13 November, 1980, Cincinnati, U.S.A.

Authors' address: Dr. P. Pévet, The Netherlands Institute for Brain Research, IJdijk 28, 1095 KJ Amsterdam, The Netherlands. 